\title{
Color Variance of Dry Coconut Wood and Its Relationship with the Density
}

\author{
Suthon Srivaro, ${ }^{\mathrm{a}, \mathrm{b}, *}$ Sataporn Jantawee, ${ }^{\mathrm{c}}$ Jaipet Tomad, ${ }^{\mathrm{d}}$ Worakan Hosakun, ${ }^{\mathrm{e}}$ and \\ Zoltán Pásztory ${ }^{\mathrm{e}}$
}

The color variance of dry coconut wood and its relationship with the wood density was explored. Coconut trunks with two different ages of 30 and 60 years old were selected for the experiment. Wood color was measured by the CIE $L^{*} a^{*} b^{*}$ or CIELAB color system on both the transverse (longitudinal-tangential plane) and cross (tangential-radial plane) sections. The results showed that all color parameters $\left(L^{*}, a^{*}, b^{*}\right)$ tended to decrease with increasing wood density for both sections in which the value on transverse section was slightly higher. At a given density, the color value of the older trunk was lower. All color parameters appeared to be related with density in a linear relationship with relatively low $R^{2}$ for both ages. The best correlation was observed for the $b^{*}$-density relationship on cross sectional samples for both trunk ages, showing $R^{2}$ values of 0.53 to 0.60 . This implies that it might be possible to use this color parameter as input for the grading of coconut wood's density.

Keywords: Coconut wood; Grading; Color

Contact information: a: Polymer Engineering program, School of Engineering and Technology, Walailak University, Thasala district, Nakhon Si Thammarat 80160, Thailand; $b$ : Materials Science and Innovation program, College of Graduate Studies, Walailak University, Thasala district, Nakhon Si Thammarat 80160, Thailand; c: Faculty of Industrial Technology, Nakhon Si Thammarat Rajabhat University, Meaung district, Nakhon Si Thammarat 80280, Thailand; d: Research Center of Excellent on Wood Science and Engineering, Walailak University, Thasala district, Nakhon Si Thammarat 80160, Thailand; e: Innovation Center, University of Sopron, 4. Bajcsy Zs str. Sopron 9400, Hungary;

*Corresponding author: ssuthon@wu.ac.th

\section{INTRODUCTION}

Coconut wood is an interesting alternative raw material for wood-based products because it is available in large amounts worldwide (Rethinam 2005). Coconut wood tissue mainly consists of fiber and parenchymatic cells. Fiber is darker, stiffer, and stronger than parenchyma cells (Fathi 2014). Generally, fibers are concentrated in the periphery zone, and their number decreases in the central zone (Meylan 1978; Fathi 2014; Srivaro et al. 2020). As a result, coconut wood color at the outer zone is darker than that of inner zone and has higher strength (Meylan 1978; Killmann 1983; Fathi 2014; Srivaro et al. 2020). To utilize this wood material, suitable property grading rules for coconut wood need to be established, as otherwise, uncertainty in properties could be expected.

Lumber grading for softwood and hardwood is generally evaluated by two methods, namely, visual and machine-stress grading (Kretschmann 2010). Sometimes a combination of both methods is used. In these methods, natural defects such as knot and slope of grain, which are visually observed, are considered as strength-reducing factors (Kretschmann 2010). Because such defects are absent in coconut wood, the lumber grading evaluation system used should be different than normal wood. It has been reported that coconut wood 
properties are strongly related to its density (Fathi 2014; Srivaro et al. 2020). This implies that grading based on density can be useful for predicting other properties of coconut wood.

This work investigated the color difference of coconut wood at various positions within a tree trunk using luminance parameters $\left(L^{*}, a^{*}, b^{*}\right)$ of the CIELAB color scale. In addition, its suitability as a potential parametric system for grading of coconut wood based on density was evaluated. The color of wood specimens was measured on the transverse (tangential-longitudinal plane) and cross (tangential-radial plane) sections at different ages. The correlation between color parameters and wood density was determined.

\section{EXPERIMENTAL}

Three coconut trunks (two 60 years old and one 30 years old) were chosen for this study from the plantation area of Thasala district (Nakhon Si Thammarat province, Thailand). The bottom part of the trunk ( $3 \mathrm{~m}$ from the ground) was selected for the experiment and sawn into specimens of dimensions $55 \mathrm{~mm}$ thick, $110 \mathrm{~mm}$ wide, and 40 $\mathrm{mm}$ long. Both 60 years old trunks were cut from the same plantation area. The coconut wood lumbers were then dried at $60{ }^{\circ} \mathrm{C}$ using a hot air oven for a week. After that, the lumber pieces were kept in a conditioning room at temperature and relative humidity of 20 ${ }^{\circ} \mathrm{C}$ and $65 \%$, respectively for about 4 months in order to obtain coconut wood with the final moisture content of $12 \%$. Prior to the measurement of wood color, both tangential and longitudinal plane of wood samples were sanded with sandpaper and both radial plane were cut using circular saw to obtain smooth surfaces. Wood color was measured on both transverse and cross sections using color analyzer (ColorFlex colorimeter, Hunter Associates Laboratory, Inc., Reston, VA, USA). The degree of lightness, rednessgreenness, and yellowness-blueness were described by the $L^{*}, a^{*}$ and $b^{*}$ parameters, respectively. Density of wood sample was also determined by dividing the weight by its volume. In total, 101 coconut wood samples were measured.

\section{RESULTS AND DISCUSSION}

Figure 1 shows the texture appearance of the 30 and 60 years old dry coconut lumbers on transverse and cross sections. By visual inspection, the color of dried coconut lumber tissue of the outer zone on transverse or cross sections appeared darker than the inner zone for both ages. The wood color measurement showed a similar trend. All color parameter values $\left(L^{*}, a^{*}, b^{*}\right)$ decreased with increasing coconut wood density (Fig. 2), indicating that high density wood was darker.

Moreover, the values of $L^{*}, a^{*}, b^{*}$ measured on the transverse and cross sections were slightly different for both trunk ages. All values measured on the transverse section were slightly higher than the values measured on the cross section, but the differences of both values were less for the older trunk. At a given density, it was found that the value of the 30 years old trunk was slightly higher for all color parameter value, indicating that wood color for the 60 years old trunk was darker. This corresponds with its texture appearance as shown in Fig. 1. The color difference between the two aged group specimens might be the result of the various extractive contents in their tissue or the presence of the thick-walled fibers in the older trunk rather than the younger one. 


\section{Transverse section}
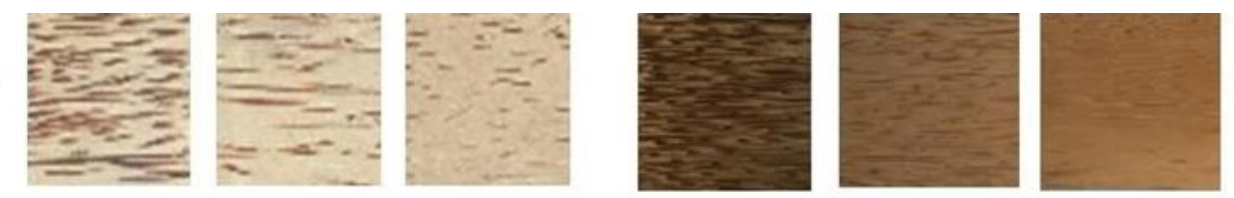

Cross
section

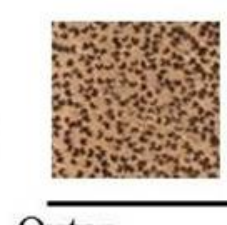

Outer

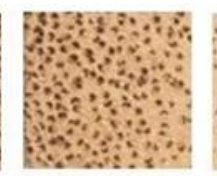

(a)

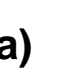

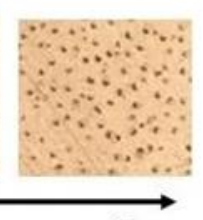

Inner Outer

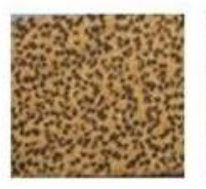

Outer

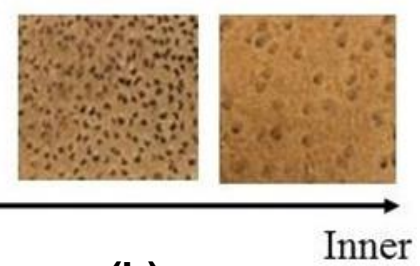

(b)

Fig. 1. Texture appearance of the dried coconut wood samples on transverse (longitudinaltangential plane) and cross (tangential-radial plane) sections at various positions along cross section (a) the 30 years old trunk and (b) the 60 years old trunk.

The color parameter values for both transverse and cross sections related with density indicated a linear relationship but with relatively low $\mathrm{R}^{2}$ value for most of them. The best correlation for the 60 years old trunk was observed from the $b^{*}$-density relationship either on transverse or cross sections, showing $\mathrm{R}^{2}$ values of 0.62 and 0.53 , respectively. For the 30 years old trunk, the best correlation was observed from the $b^{*}$ density relationship on cross section. The $\mathrm{R}^{2}$ values of the other correlations were relatively low. This result implies that it might be possible to use the $b^{*}$ value as a potential grading parameter for the density of coconut wood. However, other potential parameters that might affect the color of the dried coconut wood such as drying schedule, different plantation area of coconut tree, and positions of coconut wood along the trunk height should be further investigated in order to achieve a precise correlation for a prediction of coconut wood density in practice. 


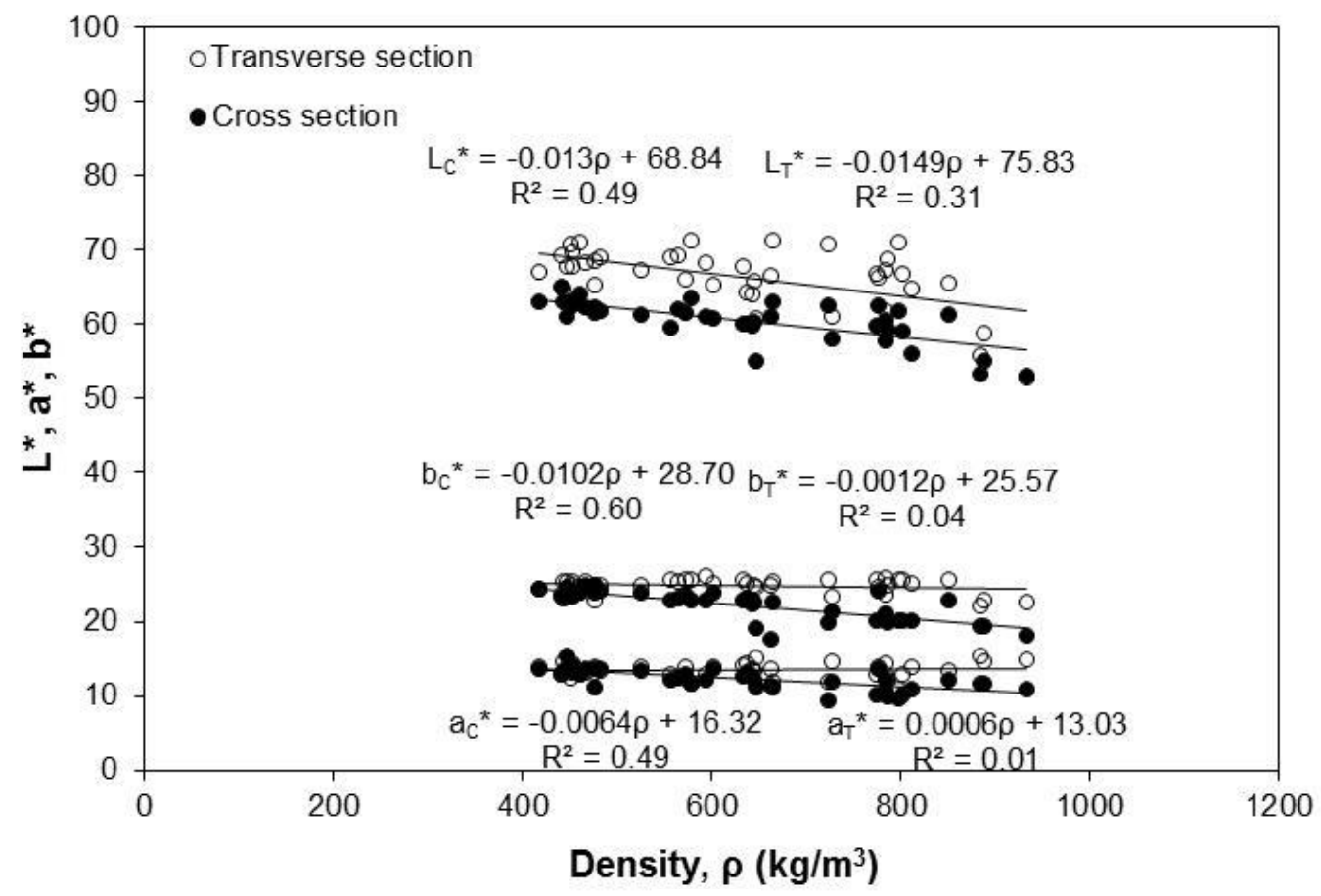

(a)

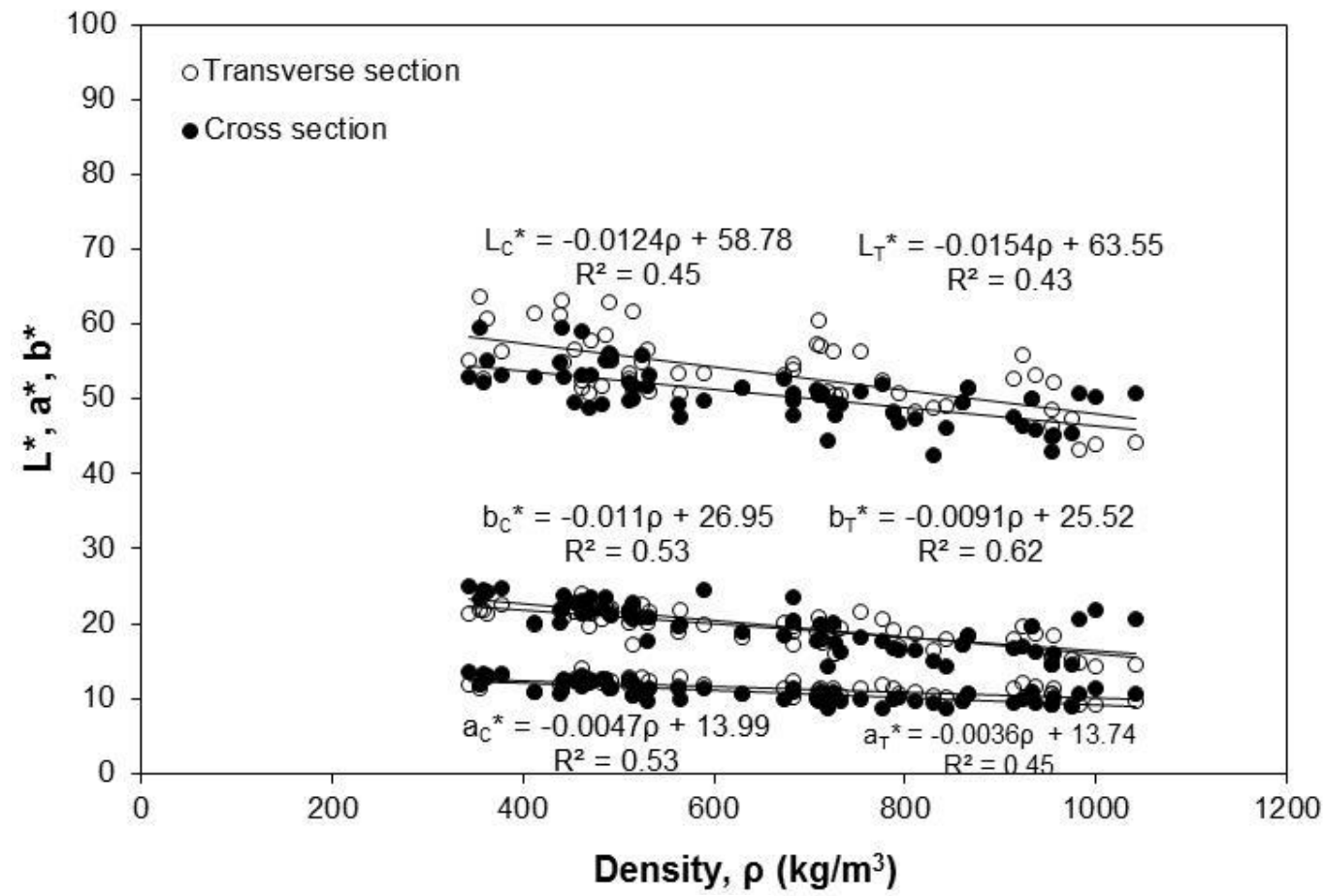

(b)

Fig. 2. Relationship between color parameter values $\left(L^{*}, a^{*}, b^{*}\right)$ measured either on transverse or cross sections and density of coconut wood, (a) the 30 years old coconut trunk and (b) the 60 years old coconut trunk. $L_{c}{ }^{*}, a_{c}{ }^{*}, b_{c}{ }^{*}=$ color parameters measured on cross section, $L_{T^{*}}, a_{T^{*}}, b_{T^{*}}$ $=$ color parameters measured on transverse section. 


\section{CONCLUSIONS}

1. All measured color parameter values tended to decrease with increasing wood density values for both transverse and cross sections. The color parameter values of the older trunk appeared to be lower for a given density.

2. All color parameter values tended to be related with wood density in a linear relationship but with low $\mathrm{R}^{2}$ value. The best correlation value was observed at the $b^{*}$ density relationship for the 60 years old trunk both on transverse and cross section $\left(\mathrm{R}^{2}\right.$ values ranged from 0.53 to 0.62 ). For the 30 years old trunk, the best correlation was observed at the $b^{*}$-density relationship on cross section $\left(\mathrm{R}^{2}=0.6\right)$. The other correlation values showed relatively low $\mathrm{R}^{2}$.

\section{ACKNOWLEDGMENTS}

This work was conducted as part of the "Sustainable Raw Material Management Thematic Network - RING 2017", EFOP-3.6.2-16-2017-00010 project in the framework of the Szechenyi 2020 Program which is supported by the European Union, co-financed by the European Social Fund. This research is also partially supported by the new strategic research (P2P) project, Walailak University, Thailand. The authors declare that they have no conflict of interest.

\section{REFERENCES CITED}

Fathi, L. (2014). Structural and Mechanical Properties of the Wood from Coconut Palms, Oil Palms and Date Palms, Ph.D. Dissertation, University of Hamburg, Germany.

Killmann, W. (1993). "Some physical properties of the coconut palm stem," Wood Science and Technology 17(3), 167-185. DOI: 10.1007/BF00372314

Kretschmann, D. E. (2010). "Stress grades and design properties for lumber, round timber, and ties," in: Wood Handbook: Wood as an Engineering Material, U.S. Department of Agriculture, Madison, WI, pp. 7-1 to 7-15.

Meylan, B. A. (1978). "Density variation within Cocos nucifera stems," New Zealand Journal of Forestry Science 8(3), 369-83.

Rethinam, P. (2005). "Asian and Pacific coconut community activities, achievements and future outlook," in: Proceedings of the International Coconut Forum, Cairns, Australia.

Srivaro, S., Tomad, J., Shi, J., and Cai, J. (2020). "Characterization of coconut (Cocos nucifera) trunk's properties and evaluation of its suitability to be used as raw material for cross laminated timber production," Construction and Building Material 254, Article ID 119291. DOI: 10.1016/j.conbuildmat.2020.119291

Article submitted: May 23, 2020; Peer review completed: July 12, 2020; Revised version received and accepted: July 22, 2020; Published: July 29, 2020.

DOI: 10.15376/biores.15.3.7074-7078 